\title{
Integrating information and navigation system in architectural landscapes of preserve- museums
}

\author{
Maria Riadova ${ }^{1, *}$ \\ ${ }^{1}$ St. Petersburg State University of Architecture and Civil Engineering, St. Petersburg, Russia
}

\begin{abstract}
The paper discusses the types of information and navigation systems, the analysis of their interaction with the architectural landscape, the criteria for developing optimal placement options. Relevance of the work is caused by the need of ensuring the availability of the environment for various visitors, to expand tourist routes. Study objective: to identify the main trends and patterns of the use of navigation systems in historical parks. Methods: archive-bibliographic, cartographic, field studies, analytical. Results: world and domestic examples of park navigation systems are analyzed, typology is performed.
\end{abstract}

\section{Introduction}

Museums play a crucial role in creating a valuable cultural and communication environment, form life's meanings. But how to ensuring a culturally available environment and how great is the need for transforming the space for the needs of museum. How does the challenge system of today's world affect this process, including the opinions of visitors. Mikhail Piotrovsky, director of the State Hermitage Museum, answers this question such a way: "There is a territory of art that the museum protects. Territory where there are rules, where no one can rudely invade. On one hand, the museum should not have censorship, on the other hand, the right to vote of the crowd" [1, p. 255].

Large museum complexes need assistance in demonstrating an architectural landscape, which is a combination of architectural buildings and structures, hydraulic systems, wooden and floral arrangements, a road and sidewalk network and small forms.

\section{Materials and methods}

Navigation park systems as small architectural forms. The objective of the work is to identify the types of navigation systems and the nature of their use. It is based on the study of numerous complex materials, including extensive descriptive data. Also, field studies have been performed.

\footnotetext{
* Corresponding author: rjadova@yandex.ru
} 


\section{Results and discussion}

\subsection{Adaptation of museum space to navigation systems}

Existing studies suggest approaches to solving the problem of adapting museum space as part of the preservation of historical heritage. The theoretical issues of preserving architectural landscapes that are objects of cultural heritage are dealt with by many Russian and foreign scientists: Yu.A. Vedenin (Concept of cultural landscape as basis for system forming of specially protected areas, 1999, Modern problems of preserving Russian estate landscape, 2001, Cultural landscape as object of heritage, 2004), C. Brandi (Theory of restoration and other works on topics of protection, conservation and restoration, 2011), S.V. Sementsov (Formation of principles of conservation of architectural and urban planning heritage of St. Petersburg on basis of patterns of its three-century urban development, 2013), F. Bandarin (Historical urban landscape: heritage management in era of urbanism, 2013), V.V. Lavrov (Actual problems of protection and use of cultural and natural heritage sites, 2016).

The issue of navigation in the parks was studied by such researchers as T.B. Dubyago, M.V. Nashchokina, S.B. Danilova [2]. E.P. Krinitsina [3] considers navigation for the park as a necessary design technique for the implementation of modern public spaces, and human communication in the architectural landscape of the park.

The relevance of the paper's topic is determined by the growing interest in the integration of new objects into the historical environment. An important problem is to identify the principles of integration and variability of information and navigation media for architectural landscapes of palace and park ensembles in the process of transforming museum complexes and cultural facilities.

Nowadays, the general digitalization and visualization of life processes, the loss of semantic codes for reading architectural landscapes, has led to the problem of disorientation of visitors in vast park areas.

In 2000, Charles Landry writes that "The physical properties of the place turned out to be shaken today by the new realities of virtual space [ ] Yet the physical, tangible world has the most important sensory characteristics that make simple being in it the most important life experience" [4, p. 72].

Infrastructure development of the park territory is a priority for any preserve-museum. Consider the trends in building up information and navigation systems, as part of an integrated component of the development strategy for preserve-museums.

\subsection{Navigation systems of Tsarskoye Selo}

In St. Petersburg, there is a brilliant ring of former imperial suburban residences, which after the October Revolution of 1917 were turned into art and historical museums. Now these are museum-reserves: Gatchina, Pavlovsk, Peterhof and Tsarskoye Selo.

The Gatchina State Museum Reserve is located $45 \mathrm{~km}$ from the center of St. Petersburg. In 1765, Catherine II presented the Gatchina Manor with nearby villages to Count Grigory Grigorievich Orlov. A year later, construction work begins here. The ensemble was created on a site with a picturesque relief, forests, lakes and consists of three parks located in series and united by one water system: Prioratsky and Palace parks, with a total area of about 300 hectares, and the Menagerie.

State Museum-Reserve "Pavlovsk". In 1777, Catherine II gave her son Pavel Petrovich and his wife Maria Fyodorovna land with an area of more than 600 hectares with surrounding villages and peasants, on the occasion of the birth of their firstborn, the future Emperor Alexander I. So, there was the village of Pavlovskoye, renamed the city in 1796 
after accession of Paul I to the throne. The ensemble of Pavlovsky Park took shape over 50 years from the end of the 1770 s to the end of 1820 . and subsequently did not undergo significant changes. The area of the park is 543 hectares.

State Museum-Reserve Tsarskoye Selo. In 1710, Tsar Peter I gave his wife Ekaterina Alekseyevna Saari manor, from this period the life of the ensemble begins. By the middle of the XIX century on the territory of Tsarskoye Selo, the task of forming a single manmade regular and spatial ensemble landscape, exemplary for all of Russia, was highest posed [5, p.27].

The extensive composition includes three palace parks with a total area of about 560 hectares - Catherine, Alexandrovsky and Babolovsky park, interconnected by water systems, a composition of the main roads and pedestrian alleys, a multi-level hierarchical three-dimensional spatial system, saturated with various works of architecture, sculpture, garden and park art, engineering structures.

During the Great Patriotic War, to a greater or lesser extent, all of the ensembles listed were destroyed, parkland was cut down, and territories were damaged by shells. From the time of restoration of museum-reserves to the present day, the inclusion of completely new small forms - entrance groups, ticket offices, pavilions, kiosks, benches, ballot boxes, signs, stands, maps - is a problem that does not have an unambiguous solution.

Architectural landscapes with a complex hierarchical system of space, previously used for walking and horseback riding by members of the crowned family and the imperial court, underwent a radical transformation in the process of museum development, eventually becoming part of the exposition space. The information and navigation system allow you to program such an architectural landscape depending on the target audience, form visiting routes, and determine the functional zoning. The key goal is to create a "readable" space that allows revealing the historical, cultural, architectural and natural potential of the palace and park ensembles.

However, Henri Lefebvre believes that if the environment can be filled, populated with signs: thereby space will be appropriated, because it is readable, that is, "plausibly" connected with society as a whole. But at the same time, readability makes reading, a gesture, an act one-time: in this "environment" there is nothing to decipher without an environment. [6, p. 89]

When choosing the type of navigation system, the following characteristics of the architectural landscape are considered: information potential, psychological comfort, scale, permeability, variability of the created environment, a landmark (figurative) system, environmental friendliness.

Thanks to the freedom of form-making, small architectural forms (hereinafter referred to as the IAF), to which information carriers belong, can be an extremely powerful means of creating any figurative content in environmental objects and systems of a very different nature [7]. The navigation object should be deliberately included in the existing system of architectural landscape, which has outstanding architectural, artistic and historical memorial value and must meet a number of criteria or properties, signs: purpose, materials and designs, form and style, general composition and details, measure of individual and typical, operational qualities, visual identification, perception by visitors, co-scale, this indicator is affected not only by the dimensions of the structure, but also by their plastic design.

The positive perception of new objects is ensured not only by their high quality, but also by optimally built connections with objects existing in this landscape context [8].

Igor Smitienko and Ella Davidyuk identify six principles of interaction of small architectural forms with the environment: ensemble - compositional unity of MAFs; dominant, in which, in addition to compositional centers, small forms have signs of senseforming dominants; thematic, when many objects are united by a common concept; theatrical, in which the subject is involved in the process of contemplation and perception 
with direct participation in the proposed action; historical - reflecting the atmosphere of the past; functional - the relationship between the object and the environment according to the function, expressed in a symbolic sign form; story - the relationship of MAFs and the environment through a common theme [9]. The analysis shows that the principles apply not only to the optical picture of space, but also to the tactile, as well as to the individual sensory field.

In 2015 to 2016, to navigate through the territory of Babolovsky and Alexander parks, a concept was developed by the authors of ZOLOTOgroup (Moscow). The design was based on the tasks of creating infrastructure and organizing event scenarios in the following areas: history, health, and ecology. A complete navigation system was formed that previously did not exist only in the Catherine Park. A special design of information media, stands with maps for easy orientation, signs of all places of attraction for visitors: entrance and recreation areas, cafes, sports grounds, and the main landscape compositions have been developed. The palace and park ensembles are distinguished by high landscape and biotypic diversity and the complex composition of flora and fauna.
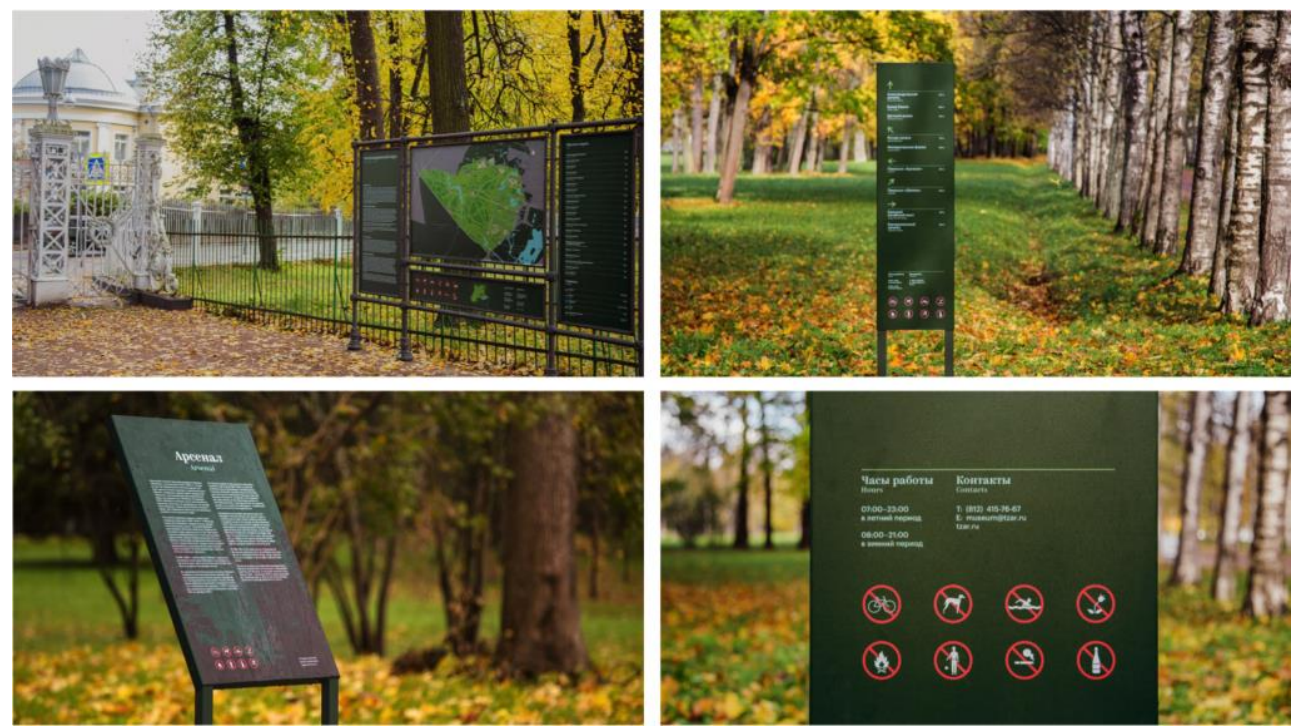

Fig. 1. Navigation system. Alexander Park. ZOLOTOgroup project performance, 2017. Photo by A.I. Chekmarev.

After the field studies and social surveys, an accessibility scheme for the objects of the Alexander Park with a promising development was developed. In the course of work, mechanisms for realizing the interests of various groups of visitors in the territory were studied; proposed solutions for arranging the points of attraction. The perspective attendance of the object as a whole and the attendance of individual architectural structures are considered, the routes of excursion routes are specified. The places of concentration of the main flows of the target audience and "quiet zones" of the park are determined. Integrated hiking, cycling, horseback riding, and seasonal (skiing) routes through navigation. Design solutions are proposed for facilities that have not yet been restored after destruction or are in the process of conservation. The proposals on creating conditions for the unimpeded movement of mobility groups of visitors across the territory are given. 


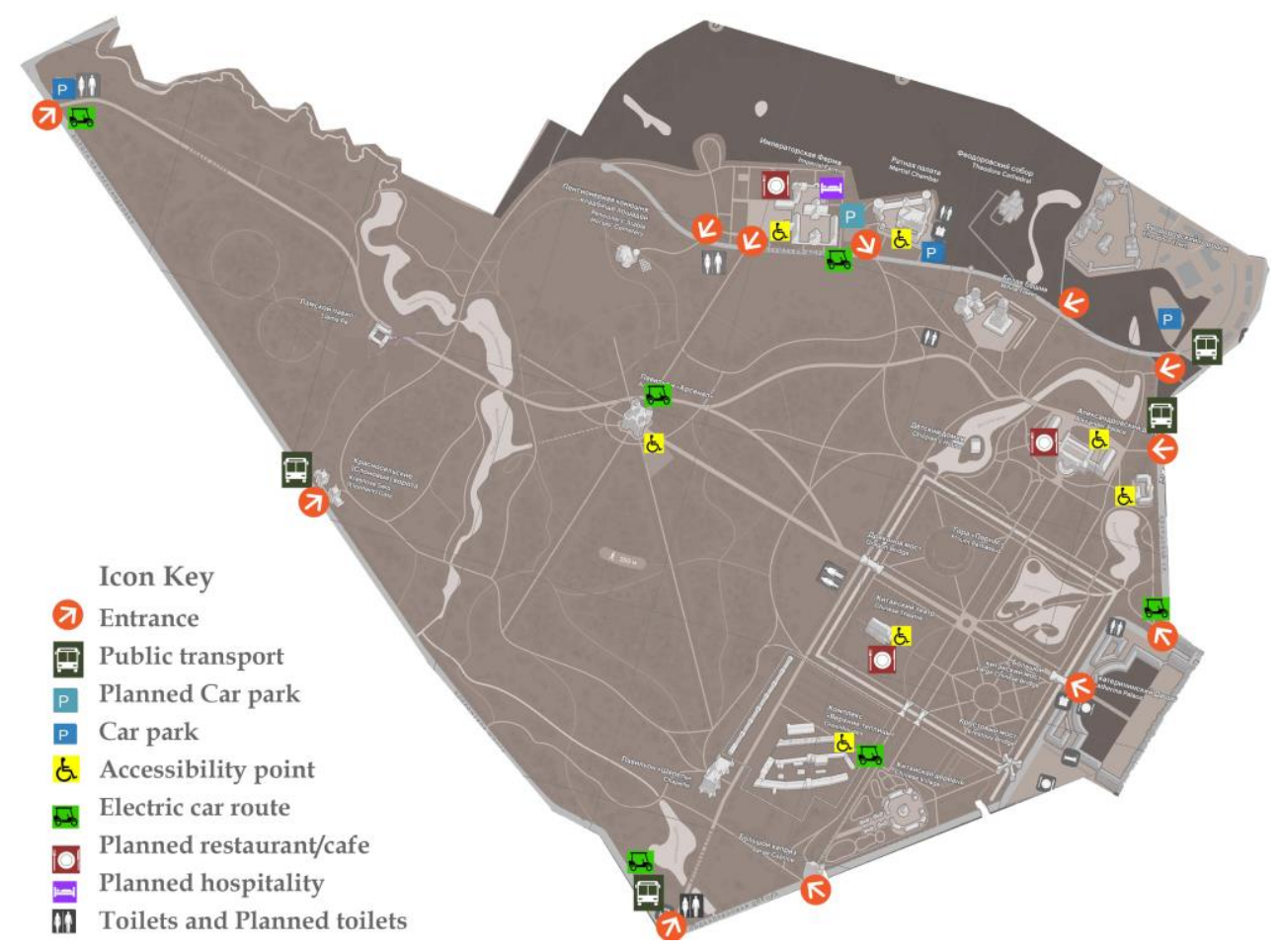

Fig. 2. Accessibility diagram. Alexander Park. Author's illustration. Such a scheme is part of the algorithm for developing an information and navigation system.

Table 1. Algorithm for developing an information and navigation system.

\begin{tabular}{|c|}
\hline Analytics \\
\hline Transport and \\
\hline walking accessibility modeling
\end{tabular}

Special attention is paid to the educational element when designing the navigation system, so infographics and special information points are developed for key attractions, where visitors can learn the history of certain monuments. 

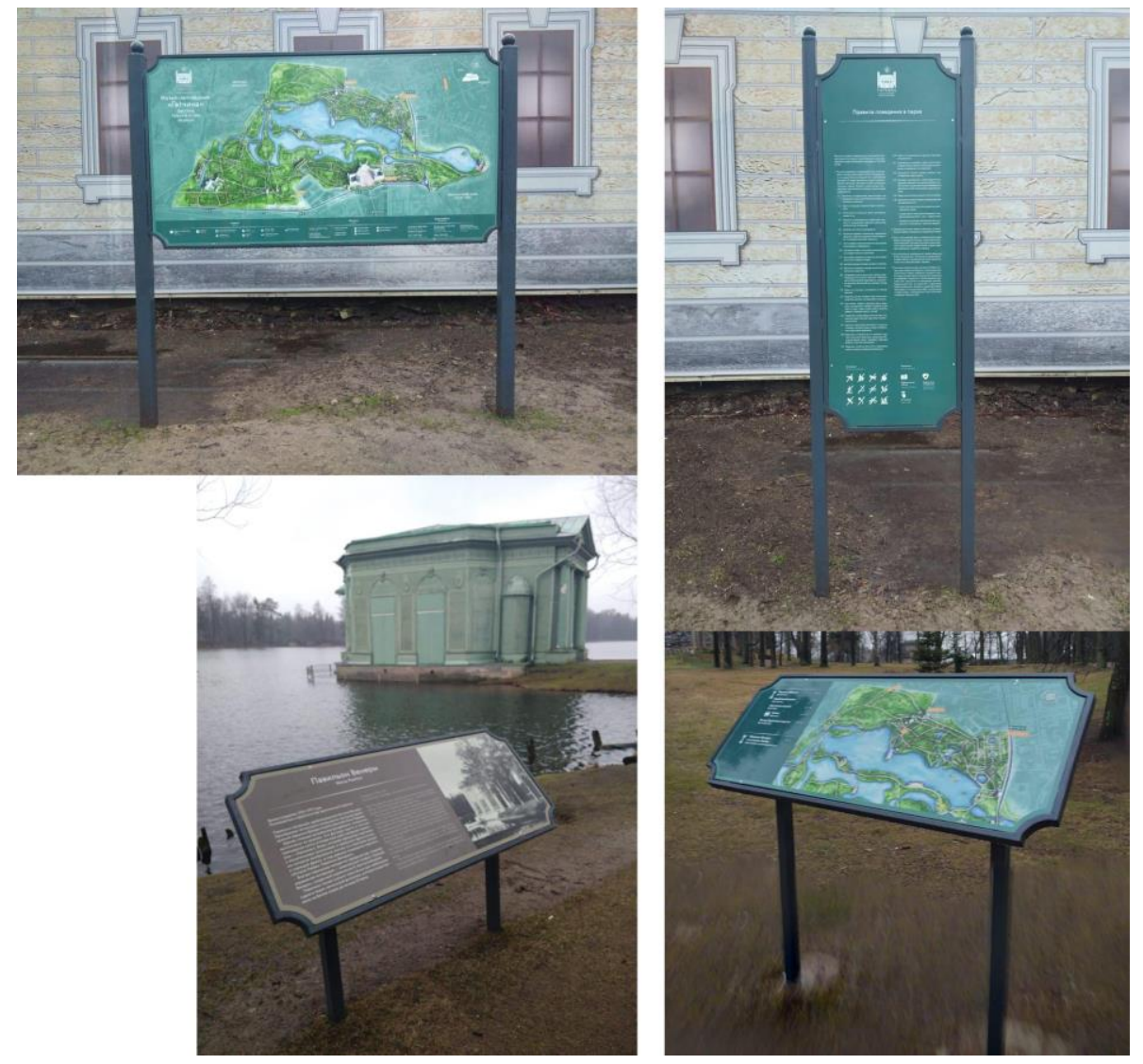

Fig. 3. Navigation system. Gatchina park. Photo by Alekseev A.N.

The considered museum-reserves, independently of each other, have developed navigation systems for their architectural landscapes over the course of several years. Comparing the selected approaches, it is revealed that the ensemble-historical principle of inclusion in the environment is the basis for design. At the same time, such a method for a monument close to stylization "can enhance or reduce the contrast of the projected environment with respect to the exposed object, however, a significant number of stylized elements and a high degree of their approximation to the historical appearance interferes with a reliable perception of the monument and its environment" [10] and it should be handled with extreme care. 


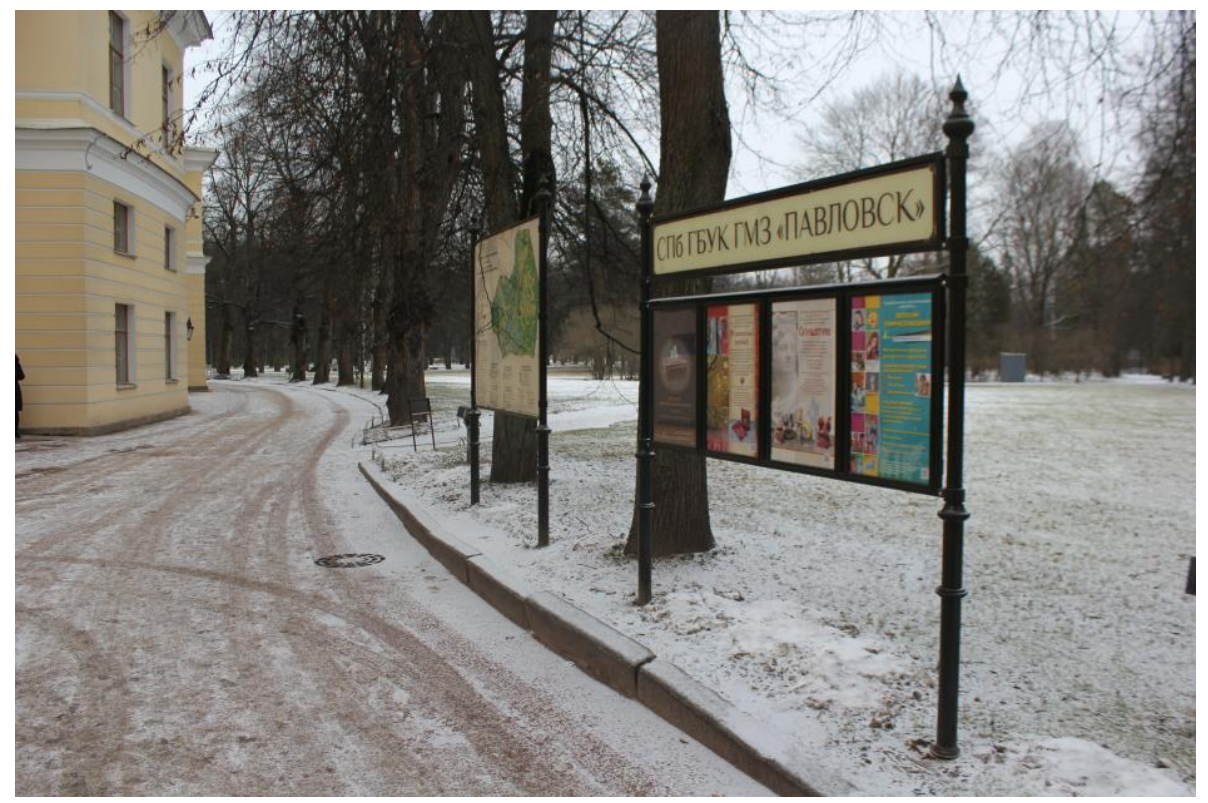

Fig. 4. Map-scheme. Pavlovsky Park. Author's photo.

\subsection{European examples of use of navigation}

The need for navigation is obvious. However, there are territories for which information media are not allowed deliberately in order to preserve unique landscape paintings. These include Rousham Park in Oxfordshire, England (17th century). It is considered the most complete surviving example of the work of the outstanding Park Builder William Kent. Currently, the garden and the house are in private ownership.

In this Park ensemble, you will not find " no signs, no diagrams, no signage, nothing to make a tourist stay familiar. Children under 15 years of age, dogs and strollers are not allowed to enter the Park. This is not a slight, but a desire to preserve and display the very Park paintings conceived by Kent, in all the splendor, without a single admixture, of subsequent centuries. And this is how visitors see them [11, p. 349]. 


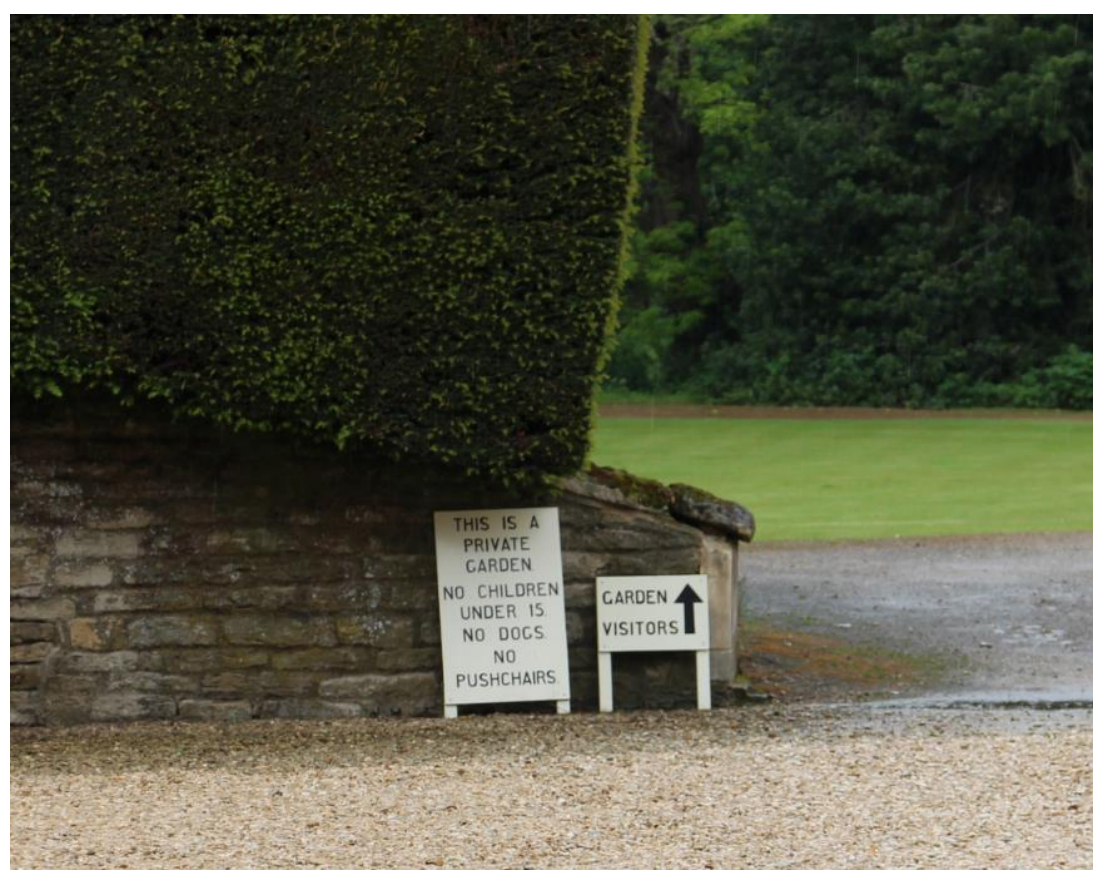

Fig. 5. Information media. Rausch. Britain. Author's photo.

\section{Discussion}

These materials are the result of an analysis of the activities of Russian museum reserves and the need for implementation and a navigation system to adapt the environment, create a "readable" space, separate streams (pedestrians, cyclists, electric cars), include objects after restoration and restoration into tourist routes, visiting of which before work was impossible. Currently, discussions are underway related to the increase in the flow of tourists to Russian parks, including from China and the need to breed various tourist groups. In this regard, the study of world practice is important. Also, tactile tablets and voice annunciators are being actively introduced, which would make it possible, using new opportunities, to ensure the accessibility of the environment for people with limited mobility. 


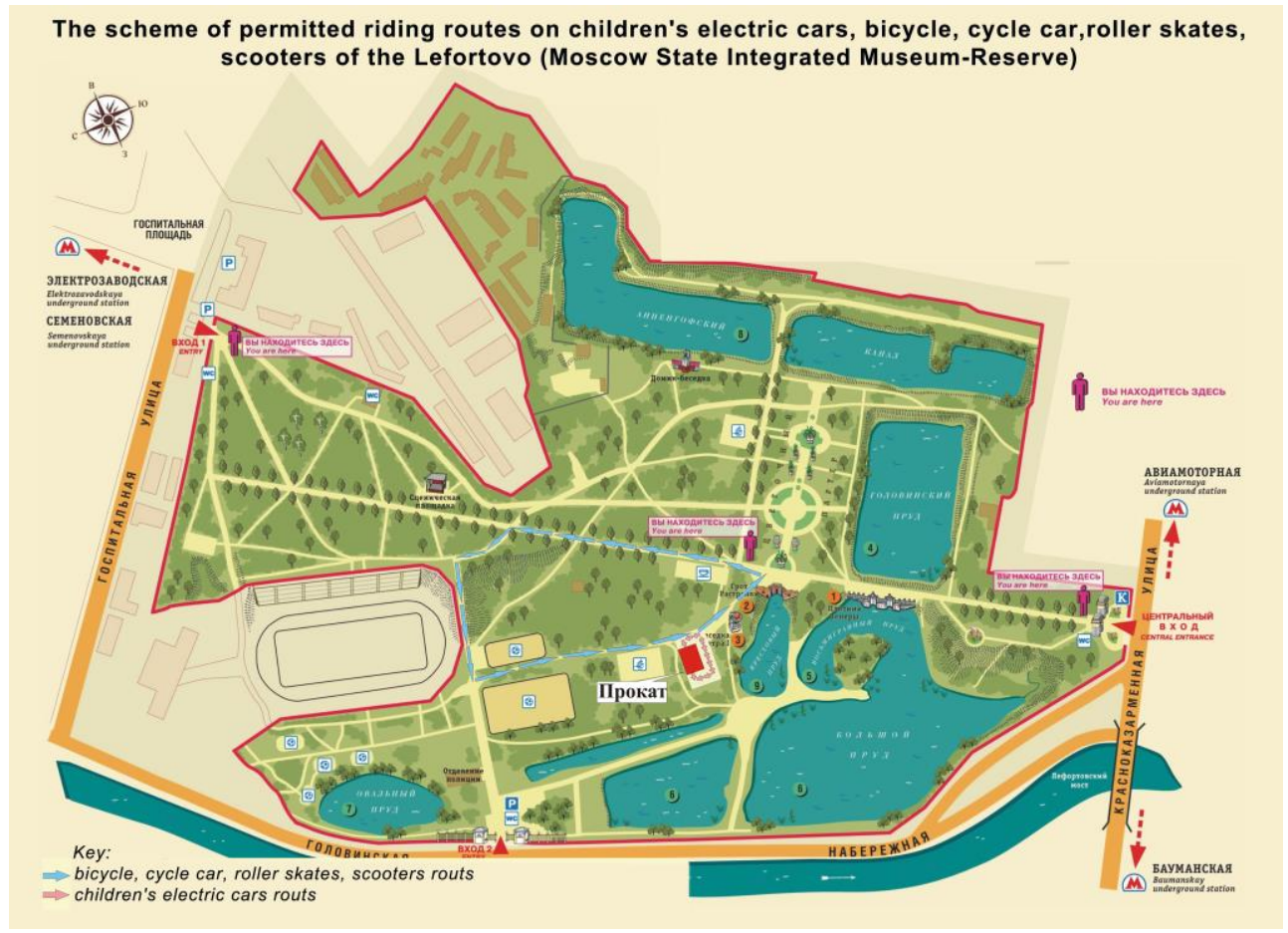

Fig. 6. Scheme of permitted routes of the Moscow State Joint Museum-Reserve "Lefortovo" (Moscow). http://mgomz.ru/wp-content/uploads/2015/04/Lefortovo.jpg

\section{Conclusions}

Thus, the analysis of world and domestic experience allows us to identify certain trends. When developing information and navigation media, it is necessary to maintain the continuity of the formation of the planning and figurative structure of the architectural landscape, to take into account the appropriateness of the application and proposals for determining specific types of navigation systems, taking into account the listed several factors and evaluation criteria.

Author thanks A.I. Chekmareva, S.A. Pavlova, A.N. Alekseev.

\section{References}

1. M.B. Piotrovsky, Vedomosti, 302, Arka, St. Petersburg (2016)

2. S.B. Danilova, Materials of IV All-Russian Scientific and Practical Conference, M.V. Zolotareva (ed.), 52-62, St. Petersburg (2018)

3. E.P. Krinitsina, Proceedings of the International Scientific and Practical Conference, 496-500 (2015)

4. Ch. Landry, Creative City (p. 399, Classic-XXI, Moscow, 2011)

5. S.V. Sementsov, Bulletin of Civil Engineers, № 6 (65), 59 (2017)

6. A. Lefebvre, Space Production (p. 432, Strelka Press, Moscow, 2015) 
7. Y.A. Kassenkova, Collection VIII International Youth Forum, V.G. Shukhov (ed.), 1061-1064, Belgorod State Technological University (2016)

8. N.P. Ovchinnikova, M.N. Ryadova, Housing, № 4, 9-11 (2004)

9. I.V. Smitienko, E.A. Davidyuk, Bulletin of Brest State Technical University. Series: Construction and Architecture, № 1, 12-16 (2016)

10. E.M. Glinternik, D.A. Shatilov, Architecton: University News, № 1 (49) (2015)

11. M.N. Ryadova, Proceedings of the International scientific XLII Dobrolyubov readings and All-Russian scientific and practical conference "In estate, at home, in paradise..." (Estate: world, myth and moment of reality), 349, Nizhny Novgorod (2018)

12. S. Vinyals-Mirabent, Journal of Destination Marketing \& Management, 12, 37-45 (2019)

13. K. McLean, International Encyclopedia of Human Geography (Second Edition), 153168 (2020)

14. J. Ablitt, Emotion, Space and Society, 34, 100648 (2020)

15. L. Deng, X. Li, H. Luo, et al., Urban Forestry \& Urban Greening, 48, 126488 (2020)

16. N. Falxa Sonti, L. K. Campbell, E. S. Svendsen, et al., Urban Forestry \& Urban Greening, 49, 126601 (2020)

17. M. Liu, S. Nijhuis, Environmental Impact Assessment Review, 82, 106376 (2020) 